\title{
ON THE USE OF MODEL BASED SYSTEMS ENGINEERING AND CAD FOR THE DESIGN OF PHYSICAL PRODUCTS
}

\author{
Meussen, Bernhard \\ NORDAKADEMIE gAG
}

\begin{abstract}
Model based systems engineering is often used as an alternative to the document based design of software or other technical systems. Its focus lies on the modelling of procedural aspects of the products, rather than on physical aspects. In mechanical engineering, the geometry and the physical properties of the product like strength, stiffness, kinematic and kinetic behaviour are described by CAD-systems. This paper tries to link model based systems engineering tools with modern CAD tools to facilitate the digitization of the development processes of physical products as part of the digitization of new digital business models.
\end{abstract}

Keywords: Systems Engineering (SE), Digital / Digitised engineering value chains, Product modelling / models

\section{Contact:}

Meussen, Bernhard

NORDAKADEMIE gAG

FB Ingenieurwissenschaften

Germany

bernhard.meussen@nordakademie.de

Cite this article: Meussen, B. (2021) 'On the Use of Model Based Systems Engineering and CAD for the Design of Physical Products', in Proceedings of the International Conference on Engineering Design (ICED21), Gothenburg, Sweden, 16-20 August 2021. DOI:10.1017/pds.2021.493 


\section{INTRODUCTION}

The digitization of industrial value chains ('industry 4.0') uses cyber physical systems (CPS) to provide new products and services and facilitates new and improved business models (Dorst et al. (2019), p. 9). Digital twins and model based engineering (MBSE) are methods the design engineer uses to satisfy the requirements of the digitization of these value chains in the engineering process of the design of machinery (Eigner et al. (2018), p. 86).

Implementation of model-based engineering (in contrast to the classical document based engineering) is easier said than done. Important contextual factors determine the required product design processes (Verein Deutscher Ingenieure (2019b), p. 14-15). Especially the business model and its implementation lead to a procedure for the digitization of the model based development of machinery. The most important steps are (Meussen (2017), p. 29):

- identification of the value chain network and their links,

- derivation of the required data and

- $\quad$ design of the model.

This paper briefly describes the example business model used in Meussen (2017). The specialty of this example business model lies in the use of individual product designs that are developed within the ordering process of the client, thus, in the individualized product development when ordered (no mass customization). The examination of the business model leads to requirements for a SysML model of a cyber-physical product for individualized production. It then presents a simple SysML model as an example, which meets these requirements by the use of computer aided design (CAD). Finally, the paper investigates its usefulness for the example business model.

The method used here follows the systems engineering approach by Haberfellner et al. (2012). By using a simple model that satisfies major requirements to represent the vision behind 'industry 4.0', the engineering method to go from coarse to fine is applied (Haberfellner et al. (2012), p. 55).

\section{EXAMPLE BUSINESS MODEL USING CPS}

Many researchers, for example Koren (2010), state that individualization shall increase the competitiveness of products. Major motivations for the individualization are specific functionality, personal taste and biometric adaption. One benefit of the digitization of industrial value chains is the individualization of products and services. The "VDI Industrie 4.0 Canvas" (Barbian et al. (2016), p. 26) describes a procedure to set up a business model for the use of individualized CPS based on the business model canvas by Osterwalder and Pigneur (2010).

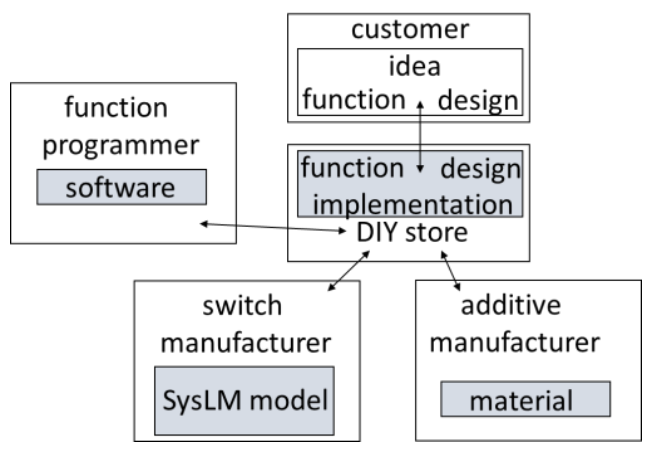

Figure 1: Interfaces of value chain actors (Meussen (2017))

Meussen (2017) uses the "VDI Industrie 4.0 Canvas" to set up the following business model: the customer wishes to buy an individual light switch with an individual frame and an individual smart switch pad (all together form a simple CPS). The customer accesses a do it yourself store (DIY store) using the shop (or the internet) and describes his idea to a trained sales person who sketches the individual design in a CAD application or the customer uploads his design himself. The DIY store processes the order and orders the standardized electrical parts at the manufacturer's site. The manufacturer is responsible for the design of the switch pad. He is the owner of the digitized product development process. The DIY store furthermore sends the STL file to an additive manufacturer who produces the individualized parts according to the customer's ideas and the adoption made by the sales person in the DIY store according to the specifications of the switch manufacturer. As soon as all parts 
are produced and send to the DIY store, the customer may pick up the switch, make the payment and mount the switch in his home.

This business model satisfies the major criteria described in Barbian et al. (2016). Meussen (2017) then translates the business model to the value chains and their network following Drumm et al. (2016). In Drumm (2016), the relevant value chains of a producing company are product development, process development, production and after sales and technical equipment. The value chain network now gives all the chain links between the different actors (client, DIY store, switch manufacturer, additive manufacturer) that are necessary to fulfil the business model.

Specific features of this value chain network are the bidirectional interaction of the customer with the DIY store, the bidirectional connection of the DIY store with the switch manufacturer and the additive manufacturer and the link between the switch manufacturer and the additive manufacturer, see figure 1. In this setup, the relevant product development process lies in the responsibility of the switch manufacturer. Similar settings are already in place, for example for B2C products like (book) shelves (i.e. www.deinschrank.de) or B2B products as robot grippers (i.e. www.egrip.schunk.com). Smart lighting switches as CPS are part of the smart home applications.

\section{REQUIREMENTS FOR INDIVIDUALIZATION OF THE CPS}

The major driver of the business model using CPS shall be the need to individualize the product to meet the customer requirements. Investigating the reasons more specifically to individualize a product (in this example the smart lighting switch) give the following requirements for the example CPS, the light switch and its SysML model:

\subsection{Individualization of colour or print}

The simplest individualization is that of colour or of printing graphical pictures onto the frame and/or the rocker of the switch. Colours are usually depending on the type of material and a wide range of technologies is available to print onto surfaces. An enterprise resource planning system (ERP system) usually manages colours by specific material numbers. In the framework here, the available colour systems and printing features to choose from may be part of the block definition diagram of the switch frame and rocker. As colouring and printing of plastic parts is standard procedure, it is not considered here.

\subsection{Individualization of the mounting}

The light switch chosen here does not require an external power supply because of the energy harvesting. As it does not interfere with the electric circuit of the light source directly, it also must not directly connect to the electric circuit. Thus, the switch may be easily mounted everywhere the customer wants it to be mounted. The individualization then covers the different materials and types of connection to the supporting wall. The switch may be glued or use a frame to be screwed onto the wall. It also may be magnetic to stick to metal objects. As this variety of individualizations is limited, it may be listed as types of the frame in the internal block diagram of the SysML model.

\subsection{Individualization of the shape}

Customers will most often chose a unique shape according to personal taste or to represent specific functions with the shape of the switch. The SysML model may cover the individualization of the shape of a physical product in several ways. The simplest would be to use drawings in the model to represent geometric constraints. More sophisticated is the use of design rules, for example by stating in the model that a certain measure may not exceed a specific value. However, rules like this often get very complex and are thus hard to put in formula or other written descriptions without a full representation of the geometry and the connected properties of the physical object.

\subsection{Individualization of the function}

It is the strength of tools like SysML to model the functionalities of a product and to visualize and document links between the functionalities and the necessary requirements. Even the relatively simple model of the light switch produces complex interdependencies within the product, see figures 5 and 8 (which is the obvious reason for using SysML in product development). In general, adding new functionalities to a SysML model is less complex than changing functionalities. 


\subsection{Provision of required data for the value chain link interfaces}

All participants of the value chain network must be able to derive the required data (see table 1) from the SysML model. Typically, a SysML model provides specific views for the different users of the model according to their needs (Weilkiens (2014)), see figure 1 for this example. This is one of the strengths of model-based engineering.

\subsection{Further requirements}

Eigner et al. (2018) give an overview over fundamental requirements for a SysML driven product development process. These requirements are interdisciplinarity, coverage of the complete product life cycle and media continuity. To cover the product life cycle, change management and version control is relevant to the usage of the SysML model. Interfaces to other software systems of the value chain like ERP systems or product data management systems (PDM systems) are required.

\section{SYSML MODEL OF THE SMART LIGHTING SWITCH (CPS)}

After having briefly discussed the results of a study on an example business model (Meussen (2017)) that meets the criteria of the vision of "industry 4.0", (see Dorst et al. (2019)), a SysML model of a simple CPS is used to investigate the benefits and the required efforts of model-based engineering with SysML. The choice of SysML, the systems engineering modelling language, to set up the design model is also discussed in Meussen (2017) and follows procedures described in Weilkiens (2014). For this paper, we assume a smart lighting switch like the Philips UID8460/10 (Signify B.V. (2020)) as a simple example for a CPS, which has the following features:

- $\quad$ power supply by energy harvesting of the switch operation and

- $\quad$ wireless communication of the switch with the smart home.

Figure 2 gives the top view of the systems engineering model of the light switch. The software used is Enterprise Architect V14 from Sparx Systems.

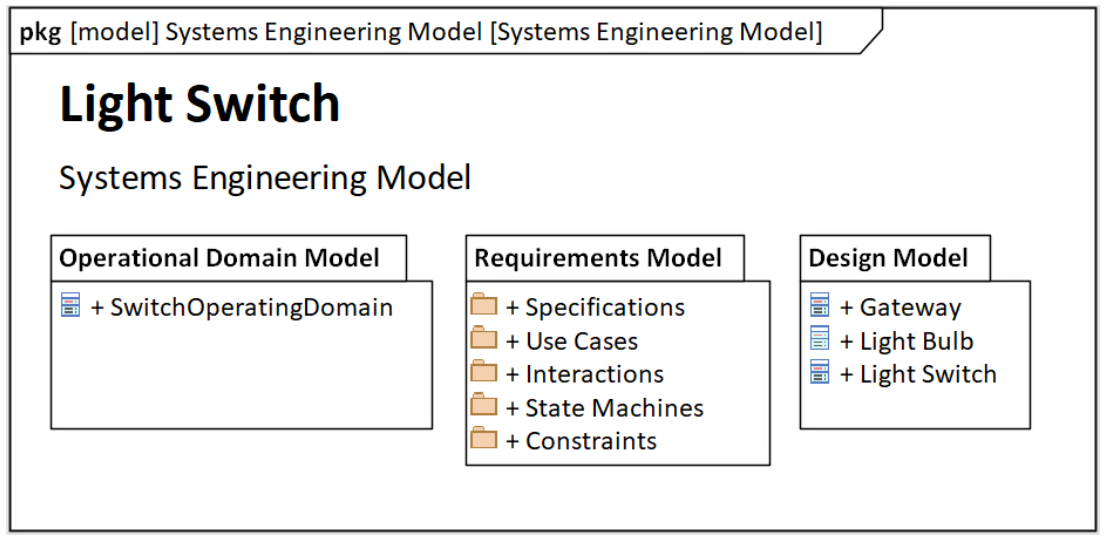

Figure 2: Light switch SysML-model

\subsection{Operation Domain Model of the Light Switch}

The operation domain model describes context in which the light switch operates. The user as well as the service technician and the smart home environment are part of this system in its operational domain, as shown in figure 3.

\subsection{Requirements Model of the Light Switch}

The requirements model documents the required technical specifications, the use cases, the interactions, the so called state machines and the constraints of the light switch. The specifications consist of the design specifications, the manufacturing process and of user requirements. The environmental requirements are here part of the manufacturing requirements, see figure 4 . Concerning the latter requirement, the model focusses on the repair of the product, thus covering the complete product life cycle. 


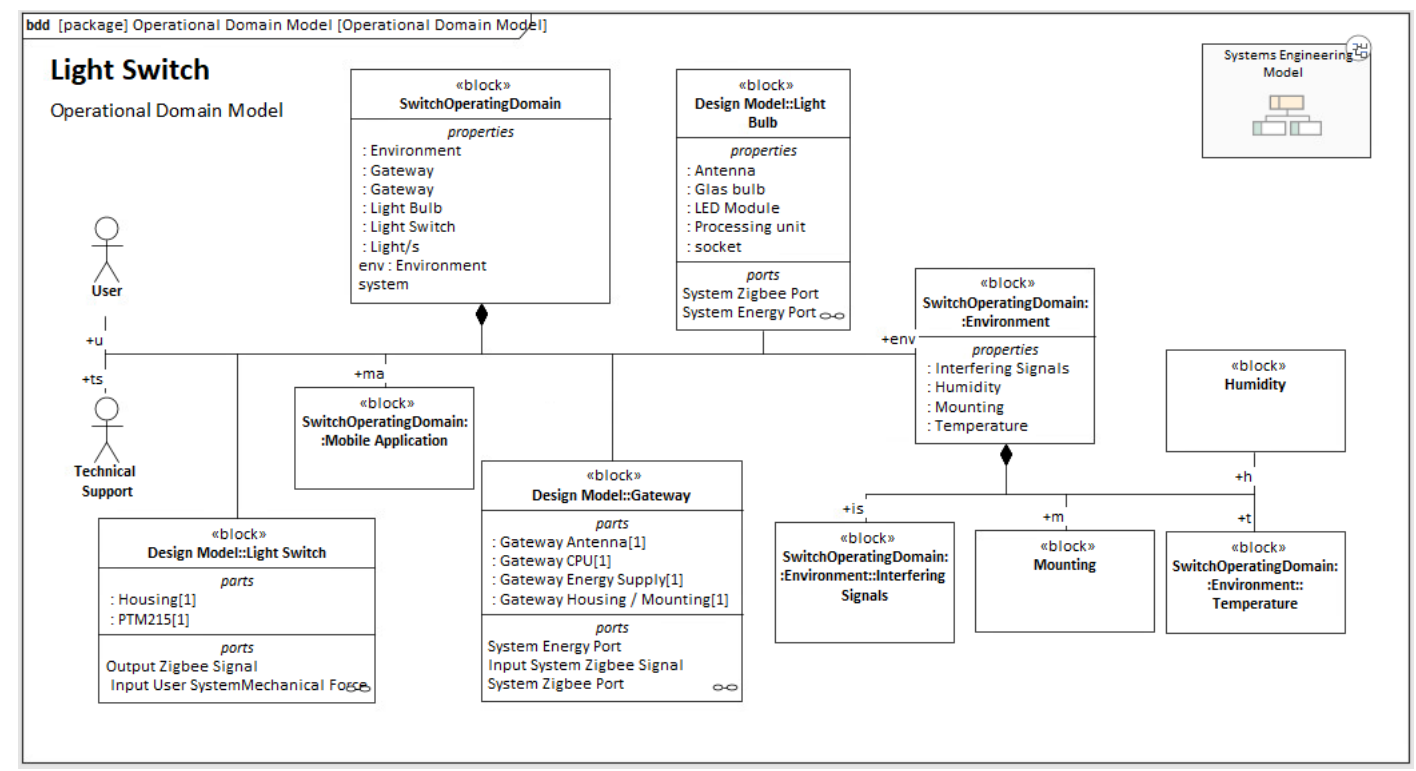

Figure 3: Operational domain model

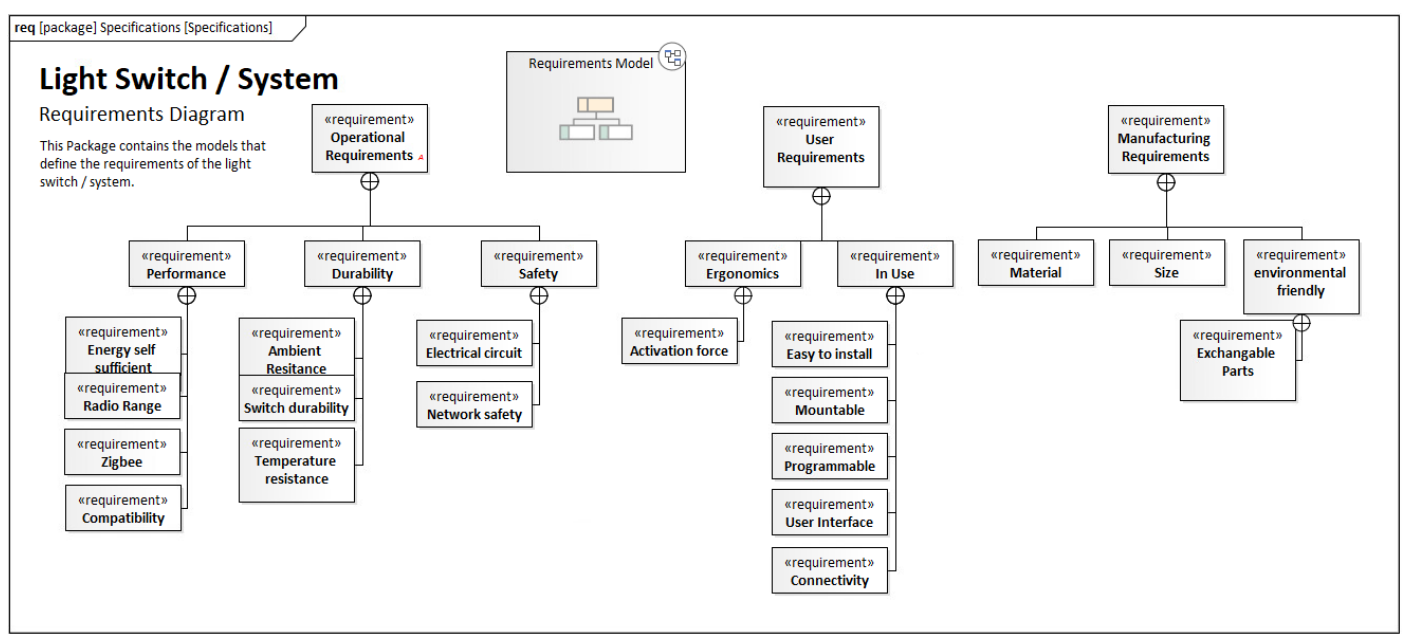

Figure 4: Specifications of the light switch

The use cases describe the main modes of operations of the switch: the setup, the actual operation and the maintenance. Both actors, user and technical support, see figure 3, may operate the switch. The operation of the switch requires the connection to a suitable network. Then, the actors teach the functionality, i.e. the ways the switch changes the lighting of the room. The switch may be reset to factory settings if required and repaired by replacing malfunctioning parts. Figure 5 gives an overview over the identified use cases and the affected specifications.

The use cases lead to interaction diagrams, which describe in more detail the processes when operating the light switch. Each state of operation of the light switch and the interconnections between them are described in "state machines". Figure 6 gives an example of the state machine "operating states".

The requirement "constraints" should cover the technical constraints, especially those of the wireless network module of the light switch. Due to the lack of technical information from the supplier, no specific further constraints were modelled. 


\begin{tabular}{|c|c|c|c|c|c|c|c|c|c|c|c|c|c|c|c|c|c|c|c|c|c|c|c|c|c|c|c|}
\hline Target + & 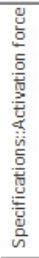 & 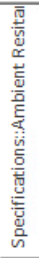 & 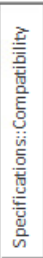 & 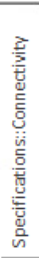 & 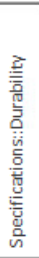 & 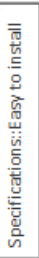 & 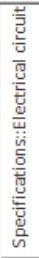 & 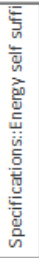 & 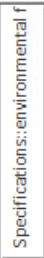 & 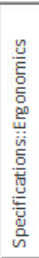 &  & 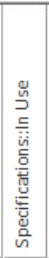 & 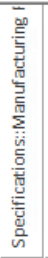 &  & 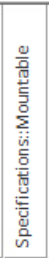 & 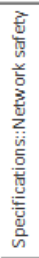 & 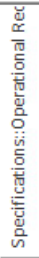 & 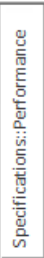 & 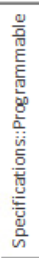 & 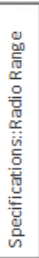 & 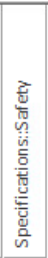 &  & 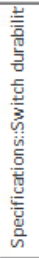 & 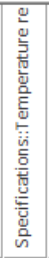 & 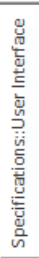 & 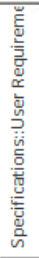 & 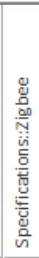 \\
\hline Use Cases::Activate Scene 1 & $\hat{\mathrm{T}}$ & & $\hat{\imath}$ & 个 & & 个 & $\hat{\mathrm{T}}$ & 个 & & & & $\hat{\mathrm{T}}$ & & & & $\hat{\mathrm{T}}$ & $\hat{\mathrm{T}}$ & $\hat{\mathrm{T}}$ & $\hat{\mathrm{T}}$ & 个 & $\hat{\mathrm{T}}$ & & & & $\hat{\mathrm{T}}$ & 个 & 个 \\
\hline Use Cases::Activate Scene 2 & 个 & & $\hat{\mathrm{T}}$ & 个 & & 个 & $\hat{\top}$ & 个 & & & & 个 & & & & $\hat{\mathrm{T}}$ & $\hat{\mathrm{T}}$ & $\hat{\imath}$ & 个 & 个 & $\hat{\imath}$ & & & & $\hat{\mathrm{T}}$ & $\hat{\mathbf{T}}$ & $\hat{\top}$ \\
\hline Use Cases::Add to group & 个 & & $\hat{\uparrow}$ & 个 & & 个 & $\hat{\mathrm{T}}$ & 个 & & & & $\hat{\top}$ & & & & $\hat{\mathrm{T}}$ & $\hat{\mathbf{1}}$ & 个 & 个 & 个 & 个 & & & & $\hat{\mathrm{T}}$ & 个 & $\hat{\imath}$ \\
\hline Use Cases::CCT Down & $\hat{\mathrm{T}}$ & & $\hat{1}$ & $\hat{\mathrm{T}}$ & & 个 & $\hat{\mathrm{T}}$ & 个 & & & & $\hat{\mathrm{T}}$ & & & & 个 & $\hat{\mathbf{T}}$ & $\hat{\mathrm{T}}$ & $\hat{\mathbf{T}}$ & $\hat{\mathrm{T}}$ & 个 & & & & $\hat{\mathbf{T}}$ & $\hat{\mathrm{T}}$ & 个 \\
\hline Use Cases::CCT Up & $\hat{\top}$ & & 个 & 个 & & 个 & 个 & 个 & & & & 个 & & & & $\hat{\mathrm{T}}$ & $\hat{\mathbf{T}}$ & $\hat{\mathrm{T}}$ & 个 & 个 & 个 & & & & $\hat{\mathrm{T}}$ & 个 & 个 \\
\hline Use Cases::Configure group & $\hat{\mathrm{T}}$ & & $\hat{\mathrm{T}}$ & $\hat{\top}$ & & 个 & $\hat{\mathrm{T}}$ & 个 & & & & 个 & & & & $\hat{\mathrm{T}}$ & $\hat{\mathrm{T}}$ & $\hat{\mathrm{T}}$ & $\hat{\mathrm{T}}$ & 个 & $\hat{\mathrm{T}}$ & & & & $\hat{\mathrm{T}}$ & $\hat{\mathrm{T}}$ & 个 \\
\hline Use Cases::Dim Down & 个 & & $\hat{\mathrm{T}}$ & $\hat{\mathrm{T}}$ & & 个 & 个 & $\uparrow$ & & & & $\hat{\alpha}$ & & & & $\hat{\mathrm{T}}$ & $\hat{\mathrm{T}}$ & $\hat{\mathrm{T}}$ & $\hat{\mathrm{T}}$ & 个 & $\hat{\mathbf{1}}$ & & & & $\hat{\mathbf{T}}$ & $\hat{\mathrm{T}}$ & 个 \\
\hline Use Cases::Dim Up & $\hat{\mathrm{T}}$ & & $\hat{\mathbf{T}}$ & $\hat{\mathrm{T}}$ & & $\hat{\mathbf{r}}$ & $\hat{\mathrm{T}}$ & 个 & & & & $\omega^{3}$ & & & & $\hat{\mathrm{T}}$ & $\hat{\imath}$ & $\hat{\mathrm{T}}$ & $\hat{\mathrm{T}}$ & 个 & $\hat{\mathbf{1}}$ & & & & $\hat{\top}$ & $\hat{\imath}$ & $\hat{\mathrm{T}}$ \\
\hline Use Cases:: Exchange Frame & & $\hat{\mathrm{T}}$ & & & $\hat{\mathrm{T}}$ & 个 & $\hat{\mathrm{T}}$ & & $\hat{\mathrm{T}}$ & $\hat{\imath}$ & 个 & & $\hat{\mathrm{T}}$ & $\hat{\mathrm{T}}$ & $\hat{\mathbf{T}}$ & & & & & & 个 & $\hat{\mathrm{T}}$ & 个 & 个 & & & \\
\hline Use Cases:: Exchange Parts & & $\hat{\top}$ & & & 个 & 个 & $\hat{\mathrm{T}}$ & & $\hat{\mathbf{T}}$ & $\hat{\imath}$ & 个 & & 个 & $\hat{\mathrm{T}}$ & $\hat{\top}$ & & & & & & 个 & 个 & 个 & 个 & & & \\
\hline Use Cases::Exchange PTM2... & & $\hat{\mathbf{T}}$ & & & 个 & 个 & 个 & & 个 & $\hat{\mathbf{T}}$ & 个 & & $\hat{\mathbf{T}}$ & $\hat{\mathrm{T}}$ & $\hat{\mathrm{T}}$ & & & & & & 个 & 个 & 个 & T & & & \\
\hline Use Cases::Exchange Rocker & & $\hat{\mathbf{T}}$ & & & 个 & 个 & $\hat{\mathrm{T}}$ & & $\hat{\mathrm{T}}$ & $\hat{1}$ & 个 & & $\hat{\mathbf{T}}$ & $\hat{\mathrm{T}}$ & 个 & & & & & & 个 & 个 & 个 & 个 & & & \\
\hline Use Cases::Exchange Wall... & & 个 & & & $\uparrow$ & 个 & 个 & & $\hat{\imath}$ & 个 & 个 & & 个 & $\hat{\mathbf{1}}$ & 个 & & & & & & 个 & $\hat{\mathrm{T}}$ & 个 & 个 & & & \\
\hline Use Cases::Operate Switch & $\hat{\imath}$ & & $\hat{\mathrm{T}}$ & $\hat{\mathrm{T}}$ & & 个 & $\hat{\mathrm{T}}$ & 个 & & & & 个 & & & & 个 & 个 & 个 & $\hat{\imath}$ & 个 & 个 & & & & 个 & $\hat{\imath}$ & 个 \\
\hline Use Cases::Reset & $\hat{\mathbf{T}}$ & & 个 & $\hat{\mathrm{T}}$ & & 个 & & & & & & 个 & & & & $\hat{\mathbf{1}}$ & $\hat{\mathbf{1}}$ & $\hat{\mathbf{1}}$ & & & 个 & & & & 个 & $\hat{\mathbf{T}}$ & 个 \\
\hline Use Cases::Setup Switch & 个 & & $\hat{\imath}$ & $\hat{\mathrm{T}}$ & & 个 & $\hat{\mathrm{T}}$ & 个 & & & & 个 & & & & 个 & 个 & $\hat{\imath}$ & $\hat{\mathrm{T}}$ & 个 & $\hat{\top}$ & & & & $\hat{\mathrm{T}}$ & 个 & 个 \\
\hline Use Cases::Show Status & $\hat{\top}$ & & $\hat{\mathbf{1}}$ & $\hat{\mathrm{T}}$ & & 个 & & & & & & 个 & & & & $\hat{\mathrm{T}}$ & $\hat{\mathrm{T}}$ & $\hat{\imath}$ & & & 个 & & & & $\hat{\mathbf{T}}$ & $\hat{\mathrm{T}}$ & 个 \\
\hline Use Cases::Switch Mainten... & $\hat{\uparrow}$ & & $\hat{\mathrm{T}}$ & 个 & & 个 & 个 & 个 & & & & 介 & & & & 个 & $\hat{\mathbf{1}}$ & 个 & 个 & 个 & $\hat{\imath}$ & & & & $\hat{\mathrm{T}}$ & 个 & 个 \\
\hline Use Cases::Turn Off & $\hat{\top}$ & & $\hat{\mathrm{T}}$ & $\hat{\mathrm{T}}$ & & 个 & $\hat{\top}$ & 个 & & & & 个 & & & & 个 & $\hat{\mathbf{1}}$ & $\hat{\top}$ & 个 & 个 & $\hat{\top}$ & & & & 个 & 个 & 个 \\
\hline Use Cases::Turn On & $\hat{\mathrm{T}}$ & & $\hat{\mathrm{T}}$ & 个 & & 个 & $\hat{\mathrm{T}}$ & 个 & & & & 个 & & & & $\hat{\mathrm{T}}$ & 个 & $\hat{\mathrm{T}}$ & 个 & 个 & $\hat{\top}$ & & & & $\hat{\mathrm{T}}$ & $\hat{\mathrm{T}}$ & $\hat{\mathrm{T}}$ \\
\hline
\end{tabular}

Figure 5: Use cases and affected specifications of the light switch

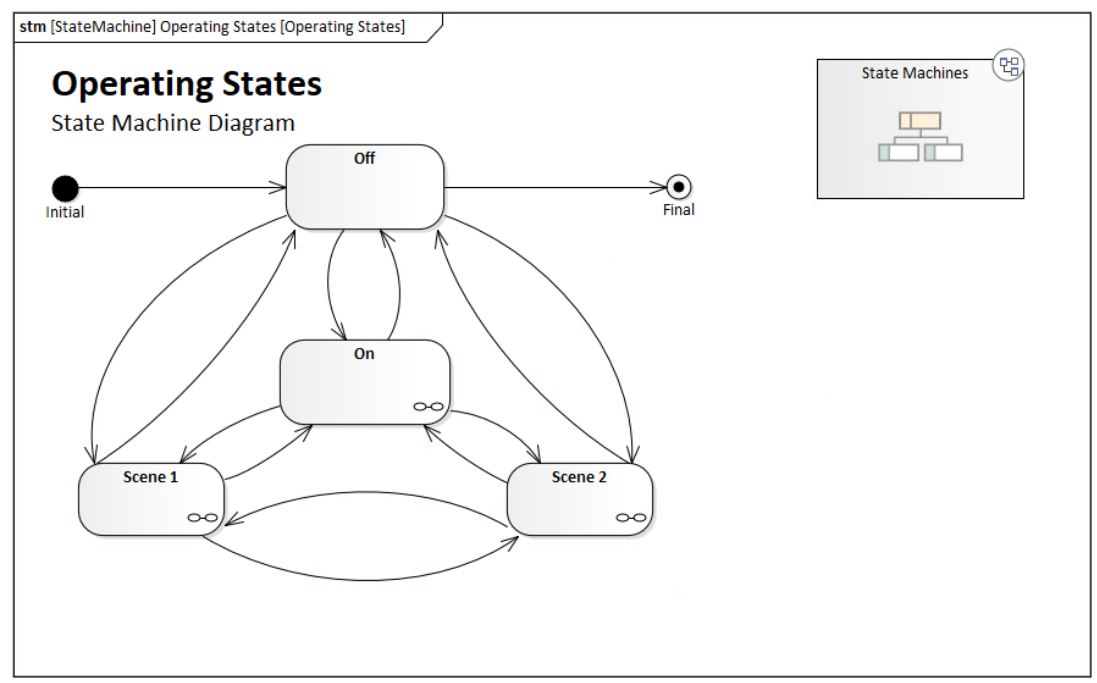

Figure 6: State machine "operating state" of the light switch

\subsection{Design Model of the Light Switch}

The design model gives the physical design of the light switch and its technical environment. Parts of this environment are the light switch itself, the gateway to interoperate with the smart home and the light bulb as the lighting source. Figure 7 gives the block definition diagram of the light switch as an example. The light switch consists of housing and the electrical switch with the energy harvesting module, the switch and the processing unit and the antenna. For each component of the block definition diagram, an internal block diagram is defined, these will be omitted here for brevity. As for the use cases, each physical component requires specifications, see figure 8 . Consequently, the physical components may be linked to the use cases, too.

This SysML-model documents the important aspects of the design, the manufacturing and the use of the light switch as a simple example of a CPS and its business model. Every actor of the business model in figure 1 may now access and manipulate the data required for his activities within the business model. 


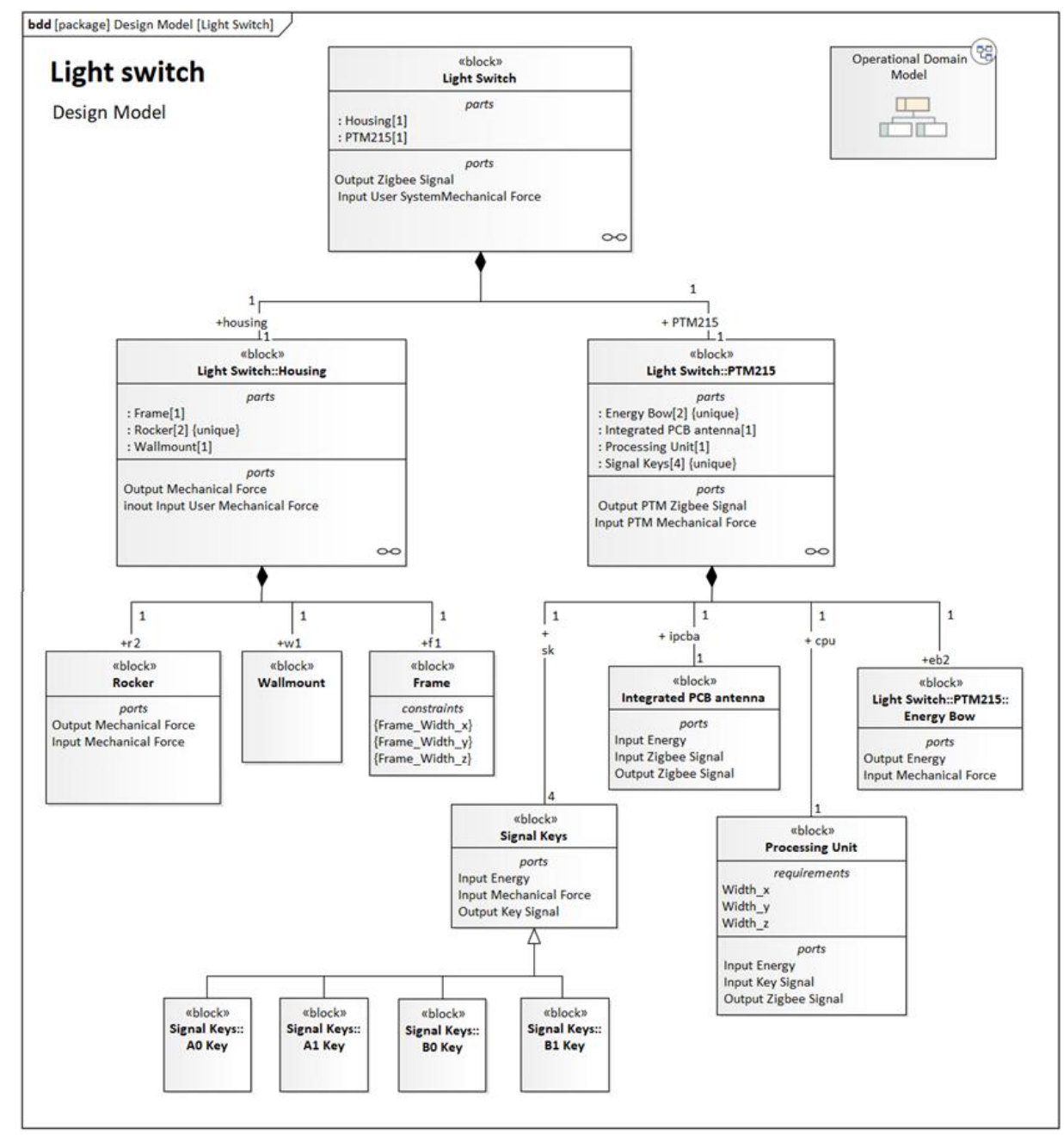

Figure 7: Block definition diagram of the light switch

\begin{tabular}{|c|c|c|c|c|c|c|c|c|c|c|c|c|c|c|c|c|c|c|c|c|c|c|c|c|c|c|c|}
\hline Target + & 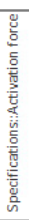 & 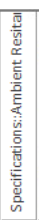 & 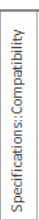 & 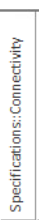 & 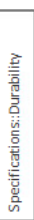 &  & 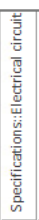 & 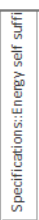 & 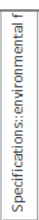 & 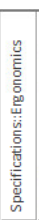 & 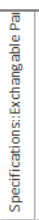 &  & 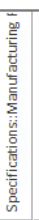 & 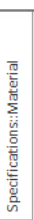 & 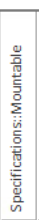 & 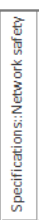 & 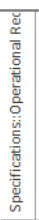 & 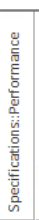 & 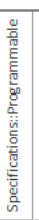 & 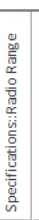 & 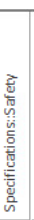 & 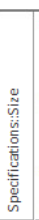 & 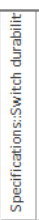 & 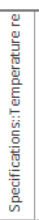 & 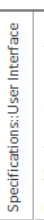 &  & 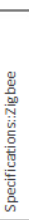 \\
\hline Design Model::A0 Key & $\hat{\imath}$ & î & & & 个 & & T & $\hat{\mathrm{T}}$ & $\hat{\mathrm{T}}$ & & & & $\hat{\mathrm{T}}$ & 个 & & & $\widehat{\mathrm{T}}$ & & & & 个 & & 个 & 个 & & $\hat{\mathbf{T}}$ & \\
\hline Design Model::A1 Key & $\hat{\mathbf{T}}$ & $\hat{\mathrm{T}}$ & & & 个 & & 个 & $\hat{\mathrm{T}}$ & $\uparrow$ & & & & $\hat{\mathrm{T}}$ & $\hat{\mathrm{T}}$ & & & 个 & & & & $\hat{\mathbf{T}}$ & & $\uparrow$ & $\hat{\mathrm{T}}$ & & $\hat{\mathbf{T}}$ & \\
\hline \multicolumn{28}{|l|}{ Design Model::Antenna } \\
\hline Design Model::BO Key & $\hat{\jmath}$ & 个 & & & $\hat{\imath}$ & & $\hat{\imath}$ & $\hat{\mathbf{T}}$ & $\hat{\mathrm{T}}$ & & & & $\hat{\boldsymbol{\top}}$ & $\hat{\mathrm{T}}$ & & & $\hat{\mathrm{T}}$ & & & & $\hat{\mathbf{T}}$ & & $\hat{\mathrm{T}}$ & 个 & & $\hat{\boldsymbol{T}}$ & \\
\hline Design Model::B1 Key & $\hat{\mathrm{T}}$ & $\hat{\mathrm{T}}$ & & & $\hat{\mathrm{T}}$ & & $\hat{\mathrm{T}}$ & $\hat{\mathrm{i}}$ & $\hat{\mathrm{T}}$ & & & & $\hat{\mathrm{T}}$ & 个 & & & 个े & & & & $\hat{\imath}$ & & $\hat{\imath}$ & $\hat{\mathbf{T}}$ & & $\hat{\mathrm{T}}$ & \\
\hline Design Model::Energy Bow & $\hat{\imath}$ & $\hat{\mathrm{T}}$ & $\hat{\imath}$ & & $\hat{\imath}$ & & $\hat{T}$ & 个 & 个 & & & & $\hat{\imath}$ & $\hat{\mathrm{T}}$ & & & $\hat{\imath}$ & $\hat{\imath}$ & & & $\hat{\mathbf{T}}$ & & $\hat{\imath}$ & $\hat{\imath}$ & & $\hat{\mathbf{T}}$ & \\
\hline Design Model::Frame & & 个 & & & $\hat{\mathrm{T}}$ & $\hat{\mathrm{T}}$ & & & $\hat{\mathrm{T}}$ & $\hat{\mathrm{T}}$ & $\hat{\mathrm{T}}$ & $\hat{\imath}$ & $\hat{\imath}$ & 个 & $\hat{\imath}$ & & $\hat{\imath}$ & & & & & $\hat{\imath}$ & 个 & $\hat{\mathrm{T}}$ & & Tे & \\
\hline Design Model::Gateway & & & $\hat{\mathbf{T}}$ & $\hat{\mathrm{T}}$ & & & $\hat{\imath}$ & & & & & $\hat{\mathbf{T}}$ & & & & 个 & & $\hat{\imath}$ & $\hat{\mathbf{T}}$ & & $\hat{\mathbf{T}}$ & & & & & & $\hat{\mathbf{T}}$ \\
\hline Design Model::Gateway An... & & & $\hat{\mathrm{T}}$ & $\mathrm{T}$ & & & 个 & & & & & $\hat{\top}$ & & & & 个 & & 个 & & $\hat{\mathrm{T}}$ & $\hat{\mathbf{T}}$ & & & & & & $\mathrm{T}$ \\
\hline Design Model::Gateway CPU & & & 个 & & & & 个 & & & & & $\hat{\imath}$ & & & & & & $\hat{\mathbf{T}}$ & $\hat{\mathbf{T}}$ & & $\hat{\mathbf{T}}$ & & & & & & $\mathrm{T}$ \\
\hline Design Model::Gateway En... & & & $\hat{\mathrm{T}}$ & & & & 个 & & & & & & & & & & & $\hat{\top}$ & & & $\hat{\mathbf{T}}$ & & & & & & 个 \\
\hline \multicolumn{28}{|l|}{ Design Model::Gateway H... } \\
\hline \multicolumn{28}{|l|}{ Design Model::Glas bulb } \\
\hline Design Model::Housing & & $\hat{\imath}$ & & & $\hat{\mathrm{T}}$ & $\hat{\imath}$ & & & $\hat{\imath}$ & 个 & $\hat{\imath}$ & $\hat{\imath}$ & 个 & 个 & $\hat{\imath}$ & & & & & & & $\hat{\mathrm{T}}$ & $\hat{\imath}$ & 个 & & $\hat{\mathrm{T}}$ & \\
\hline Design Model::Integrated ... & & 个 & & 个े & & & 个 & $\hat{\imath}$ & $\hat{\mathrm{T}}$ & & & $\hat{\imath}$ & 个 & 个 & & 个̂ & & $\hat{\imath}$ & & $\hat{\mathrm{T}}$ & $\hat{\top}$ & & & 个े & & & $\hat{\mathrm{T}}$ \\
\hline \multicolumn{28}{|l|}{ Design Model:LED Module } \\
\hline \multicolumn{28}{|l|}{ Design Model::Light Bulb } \\
\hline Design Model:Light Switch & $\hat{\imath}$ & 个 & $\hat{\imath}$ & $\hat{\imath}$ & $\hat{\mathrm{T}}$ & $\hat{\mathbf{T}}$ & 个 & $\hat{\mathrm{T}}$ & $\hat{\mathrm{T}}$ & $\hat{\mathrm{I}}$ & $\hat{\imath}$ & $\hat{\imath}$ & $\hat{\mathbf{T}}$ & $\hat{\mathbf{T}}$ & $\hat{\mathbf{T}}$ & $\hat{\uparrow}$ & $\hat{\imath}$ & $\hat{\imath}$ & $\hat{\mathbf{1}}$ & $\hat{\top}$ & Tे & $\hat{\mathbf{T}}$ & $\hat{\imath}$ & $\hat{\mathbf{1}}$ & $\hat{\imath}$ & $\hat{\mathbf{T}}$ & $\hat{\top}$ \\
\hline \multicolumn{28}{|l|}{ Design Model::Processing ... } \\
\hline Design Model::Processing ... & & $\hat{\mathbf{T}}$ & $\hat{\mathrm{T}}$ & & & & $\hat{\mathrm{T}}$ & † & 个 & & & $\hat{\uparrow}$ & $\hat{\uparrow}$ & $\hat{\top}$ & & & & $\hat{\imath}$ & $\hat{\imath}$ & & $\hat{\mathbf{T}}$ & & & $\hat{\imath}$ & & & $\hat{\mathrm{T}}$ \\
\hline Design Model::PTM215 & & $\uparrow$ & $\hat{\imath}$ & & & & $\hat{\mathbf{1}}$ & $\hat{\imath}$ & $\hat{\mathbf{T}}$ & & & $\hat{\imath}$ & $\hat{\imath}$ & $\hat{\mathbf{T}}$ & $\hat{\mathbf{t}}$ & & & $\hat{\mathbf{1}}$ & $\hat{\mathbf{t}}$ & $\hat{\mathrm{T}}$ & $\hat{\mathbf{t}}$ & & & $\hat{\mathbf{1}}$ & & & $\hat{\mathbf{T}}$ \\
\hline Design Model::Rocker & $\hat{\imath}$ & $\hat{\mathrm{T}}$ & & & $\hat{\mathrm{T}}$ & $\hat{\mathrm{T}}$ & & & $\hat{\mathrm{T}}$ & $\hat{\mathrm{I}}$ & $\hat{\imath}$ & $\hat{\imath}$ & $\hat{\imath}$ & $\hat{\mathbf{T}}$ & $\hat{\mathrm{t}}$ & & $\hat{\mathrm{T}}$ & & & & & $\hat{\imath}$ & 个 & $\hat{\mathbf{1}}$ & $\hat{\mathbf{T}}$ & $\hat{\imath}$ & \\
\hline Design Model::Signal Keys & $\hat{\mathrm{T}}$ & $\hat{\mathrm{T}}$ & & & $\hat{1}$ & & 个 & $\hat{\mathrm{T}}$ & $\uparrow$ & & & & $\hat{\mathrm{T}}$ & $\hat{\mathbf{T}}$ & & & $\hat{\mathrm{T}}$ & & & & 个 & & $\hat{\imath}$ & 个े & & $\hat{\mathrm{T}}$ & \\
\hline \multicolumn{28}{|l|}{ Design Model::socket } \\
\hline Design Model::Wallmount & & 个 & & & $\hat{\mathrm{T}}$ & $\hat{\mathrm{T}}$ & & & $\hat{\mathrm{T}}$ & † & $\hat{\mathrm{T}}$ & $\hat{\mathbf{T}}$ & $\hat{\mathbf{T}}$ & $\hat{\top}$ & & & $\hat{\imath}$ & & & & & $\hat{\mathrm{T}}$ & $\hat{\jmath}$ & 个 & & $\hat{\mathbf{T}}$ & \\
\hline
\end{tabular}

Figure 8: Components of the design model and affected specifications of the light switch 


\section{USAGE OF THE SYSML MODEL IN THE EXAMPLE BUSINESS MODEL}

\subsection{Integration of the SysML model and CAD}

As stated above, some types of individualization are inherent to the product, like the type of mounting of the smart switch in the smart home. Due to the energy harvesting ability of the smart switch and the wireless communication with the smart home applications, the position of the switch is free and may be changed when needed. Other individualizations, like colour or printing, are already state of the art. The functionality of the CPS lies in the coding of the switch and the functionality of the smart home. To describe these functions is the core ability of SysML (see for example the state machine in figure 6). From these diagrams, software systems like Enterprise Architect are able to derive code for the required hardware. Changing the functionality may be checked against the requirements and the specifications of the product (see figures 5 and 8).

In engineering, it is state of the art to use $3 \mathrm{D}$ CAD systems to design, represent and simulate the behaviour of physical objects. Figure 9 shows the CAD-model of the light switch. The CAD-software used is Autodesk Inventor 2020. As many modern CAD-systems, Autodesk Inventor 2020 offers a wide range of functionalities.

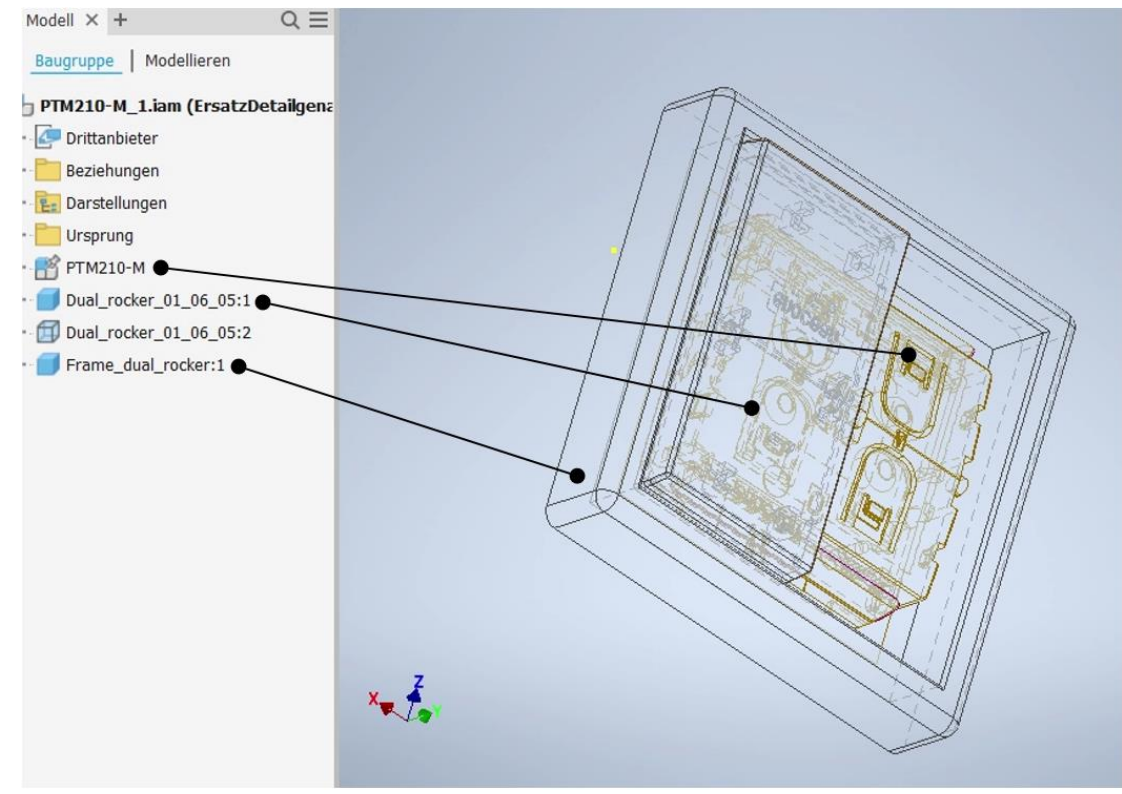

Figure 9: CAD-model of light switch in autodesk inventor 2020

Currently, intensive research is done on the connection of 3D CAD and CAE (computer aided engineering) to model based engineering (see for example Eigner et al. (2018)). Data exchange between the SysML-model in the software Enterprise Architect and the CAD-software Autodesk Inventor i.e. is possible using standard import and export features of both programs via XML- or CSV-files.

As an example, the shape of the housing of the light switch shall be object to individualization. In the SysML-model, the free width required by the switch module PTM210-M (see figure 9) is listed as a constraint in the SysML-model. With a simple rule, it is possible to check this requirement against the free width which the frame in figure 9 offers, if the necessity to check this feature has been identified when setting up the model, see figure 10.

More complex geometric checks are possible using the collision checking feature of the CADprogram. In figure 11, the value of the parameter frame 'Frame_width_z', the free width of the frame in z-direction, changes from $51 \mathrm{~mm}$ to $40 \mathrm{~mm}$. This change leads to the remodelling of the frame. The CAD-program checks for collisions, finds the colliding volumes (red areas in figure 11) and returns this information to the SysML-model as a violation of requirements. 


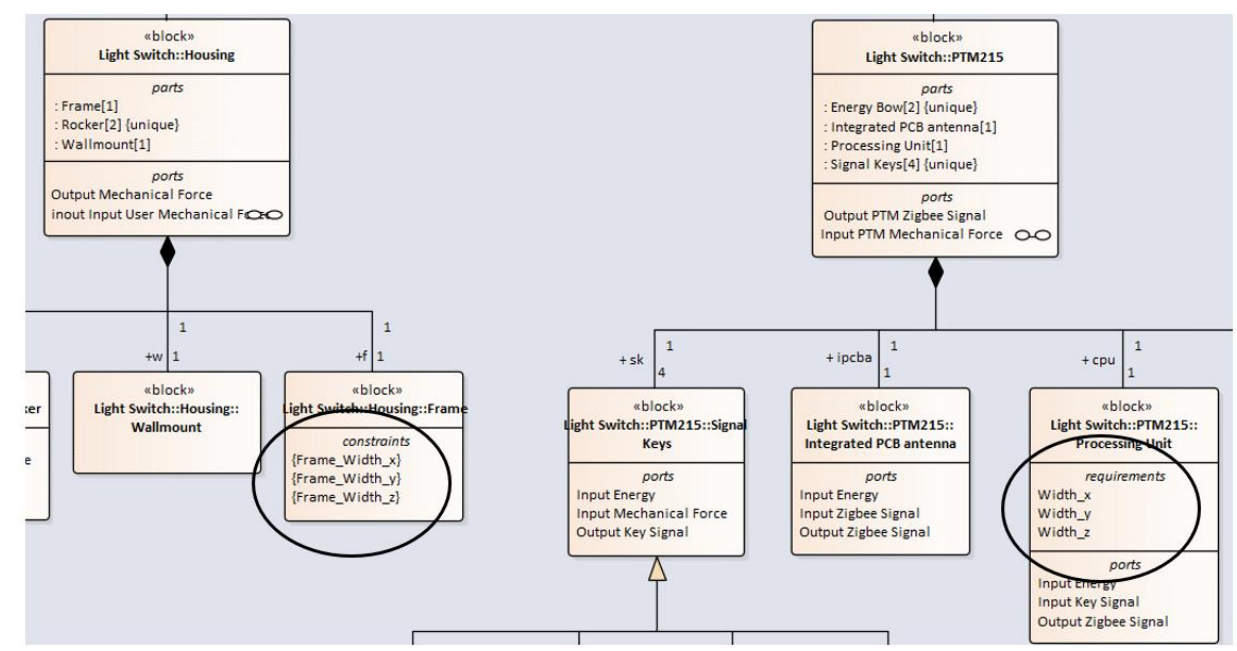

Figure 10: Example of representation of geometric features in SysML

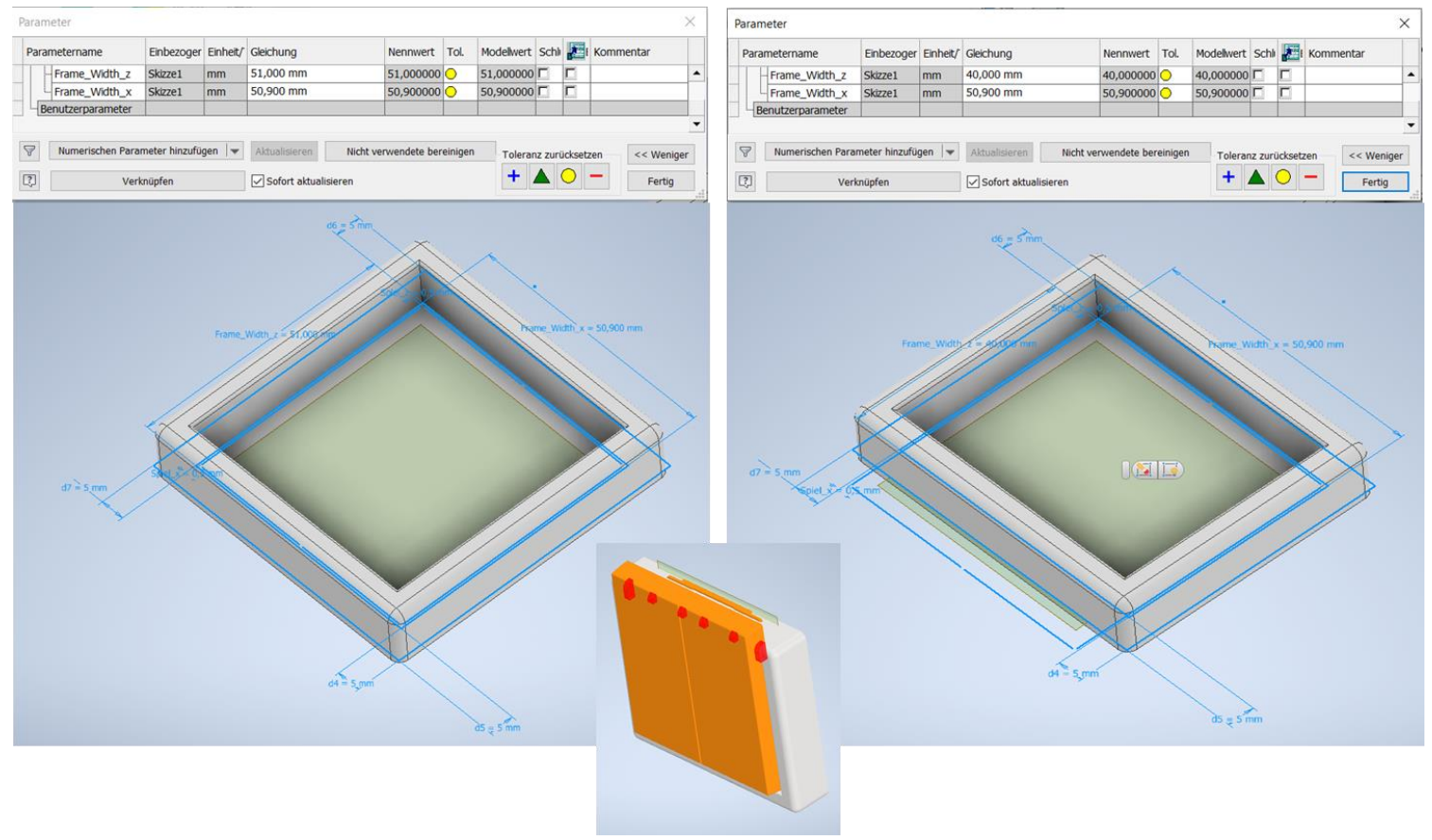

Figure 11: Parameterized modelling and collision checking in CAD-programs

Using the parameterized modelling features of CAD systems, individualizations of the geometry may be checked that have not been formulated in mathematical rules at all.

Checking for geometric constraints is only one possible use of the functionality of CAD-programs in model based design with SysML As 3D CAD is the most comprehensive way to digitize geometric features of physical objects, all types of simulations performed by CAD-programs using this geometry give useful information to the SysML model. Besides the geometry, the SysML model may than use other features of physical object like deformation, strength and kinematic behaviour, which are essential to the design of mechanical objects. Using the CAM (computer aided manufacturing) features of modern CAD-programs, even the link to more comprehensive considerations of manufacturing processes are possible. As CAD systems deliver models for augmented or virtual reality applications, also advanced virtual presentation of the individualized geometry is a possible outcome of the product model in SysML.

\subsection{Use of integrated SysML model and CAD in PLM}

The integration of CAD systems in PLM and especially in ERP and PDM systems is state of the art. Eigner (2015) discusses the integration of MBSE in the product life cycle management (PLM) in different variations. Eigner et al. (2018) presents a procedure to use MBSE with SysML to develop CPS. In these works, the procedure to use a SysML model in the PLM and its linkage to other PLM 
software systems is discussed, covering many practical aspects of the use of MBSE like change management or versioning. For more details, see Eigner (2015) and Eigner et al. (2018).

MBSE provides views on the model, which may arrange information according to the need of the intended user (Weilkiens (2014)). This feature is useful to provide the information required by the partners of the value chain (Drumm et al. (2016)), see figure 1 for this example.

\section{CONCLUSION}

Model based design of physical products is a method that gives designers the opportunity to cover the whole requirements of a business model and of the complete life cycle in the design process. Its main benefit is the representation of all available information of the product to every instance linked to the value chain. SysML is a modelling language that gives the framework to the model based design. However, as the strengths of SysML is the procedural description of technical systems, which is extremely useful i.e. for designing software, electronics or process technologies, its weakness is the insufficient ability to describe complex geometry. The description of complex geometry is necessary for the design of physical objects. 3D CAD programs are the state of the art to do this. Thus, the linkage of SysML (or other modelling tools) and CAD systems is essential to the success of the digitization of the development processes of physical products in fully digitized value chains.

Using a model that combines SysML and CAD and integrates these into PLM gives the opportunity to establish a business model, which is able to produce individualized products without using mass customization. Design operations are only required when customers order the individualized solutions.

\section{REFERENCES}

Barbian, M., Gräßler, I., Piller, F., Gülpen, Ch., Welp, P., Kamal, H., Buchegger, Th., Splettstößer, U., Schmidt, M., Schmalfuß, M., Wilkie, J., Krüger, M., Schole, Ph., Bergmair, B., Neuenhanh, M. and Dirzus, D. (2016), Statusreport Digitale Chancen und Bedrohungen - Geschäftsmodelle für Industrie 4.0, Available at https://www.vdi.de/ueber-uns/presse/publikationen/details/geschaeftsmodelle-fuer-industrie-40-digitalechancen-und-bedrohungen (25.11.2020).

Dorst, W., Falk, S., Hoffmann, M., Lehmann-Brauns, S., Löwen, U., Plass, Ch., Polenz, C., Posselt, Th., Riperda, Ch., Schmidt, F. and Unkelhäußer, L (2019), Digital business models for Industrie 4.0. Federal Ministry for Economic affairs and Energy (BMWI). Available at: https://www.plattformi40.de/PI40/Redaktion/EN/Downloads/Publikation/Digital-business-models.html (25.11.2020).

Drumm, O., Eckhardt, R., Fay, A., Gutermuth, G., Krumsiek, D., Löwen, U., Maikat, Th., Mersch, T., Schertl, A., Schwindler, Th., Schleipen, M. and Schröck, S. (2016), Statusreport durchgängiges Engineering in Industrie 4.0-Wertschöpfungsketten. Available at: https://www.vdi.de/ueber -uns/presse/publikationen/ details/industrie-40-wertschoepfungsketten (25.11.2020)

Eigner, M. (2015), "How to Integrate MB(S)E and PLM", In OMG Meeting 15.-19.06.2015, Berlin. Available at: https://www.omg.org/news/meetings/tc/berlin-15/special-events/mfg-presentations/eigner.pdf $(10.03 .2021)$

Eigner, M., Dickopf, T., Apostolov, H. (2018), "Interdisciplinary Design Methods and Processes to Develop Cybertronic Products", Konstruktion, Vol. 2018, No. 11/12, pp. 84-90.

Haberfellner, R., Fricke, E, Weck, O. and Vössner, S. (2012), Systems Engineering, Orell Füssli, Zürich.

Koren, Y. (2010), The Global Manufacturing Revolution: Product-Process-Business Integration and Reconfigurable Systems, John Wiley \& Sons.

Meussen, B. (2017): Value Chains and Digitization of Product Development Processes. In: Proceedings of the 21. International Conference on Engineering Design (ICED17), Vol. 5: Design for X, Vancouver, Canada, 21.-25.08.2017, pp. 21-30.

Osterwalder, A., Pigneur, I. (2010), Business Model Generation, Wiley, New Jersey.

Signify B.V. (Ed.) (2020), UID8460/10 ZGP Switch Dim 4B. Available at: https://www.lighting.philips.com/main/prof/lighting-controls/indoor-accessories/indooraccessories/913700364103_EU/product (25.11.2020)

Verein Deutscher Ingenieure (2019a), VDI 2221 Part 1: Design of technical products and systems - Model of product design, Beuth, Berlin.

Verein Deutscher Ingenieure (2019b), VDI 2221 Part 2: Design of technical products and systems Configuration of individual product design processes, Beuth, Berlin.

Weilkiens, Tim (2014), Systems Engineering mit SysML/UML, dpunkt.verlag, Heidelberg. 